DOI: http://doi.org/10.4038/sljp.v22i1.8094

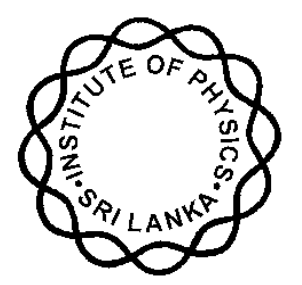

INSTITUTE OF PHYSICS - SRI LANKA

Research Article

\title{
Physical characterizations of casein by using electrochemical and spectroscopic techniques
}

\author{
T.R. Senevirathne*, G.C. Wickramasinghe, K.T. Hettiarachchi and V.P.S Perera \\ Department of Physics, Faculty of Natural Sciences, \\ Open University of Sri Lanka, Nawala, Nugegoda
}

\begin{abstract}
Casein is the major protein present in cow's milk. Lowering the $\mathrm{pH}$ of cow's milk by addition of acids, natural casein can be precipitated, which can be utilized in fabricating thin film of polymer matrix for electrodes of optoelectronic devices. In the current study, casein was isolated by using several organic and inorganic acids. As organic acids, acetic, lactic, formic and ascorbic acids were used and $\mathrm{H}_{3} \mathrm{PO}_{4}, \mathrm{H}_{2} \mathrm{SO}_{4}$ and $\mathrm{HNO}_{3}$ were used as the inorganic acids. Thin films of casein were deposited on conducting tin oxide glass plates by using the casein precipitated with each acid and electrochemically characterized. But any significant difference could not be seen in the above measurements, where the same yield and results were obtained with all acids. Therefore, in further studies, casein isolated from acetic acid was used because of the safeness in using diluted acetic acid solution. These casein films were physically characterized by using impedance and optical spectroscopic techniques. Mott-Schottky analysis has shown that casein is having an n-type conductivity with flat band potential at $0.61 \mathrm{~V}$. The impedance spectroscopic analysis was used to calculate the electrical conductivity and dielectric constant of casein which were found to be $1.13 \times 10^{-2} \mathrm{mS} / \mathrm{m}$ and 6.6 respectively. The band gap of synthesized casein was determined by drawing tauc plot using the UV visible spectroscopic data which was found to be $3.9 \mathrm{eV}$. Fourier transform infrared spectra of casein sample were recoded to confirm the presence of functional groups in the synthesized compound. With this characterization, it was evident that casein is a prospective material to fabricate novel optoelectronic devices.
\end{abstract}

Keywords: Casein, Insulator, Thin film polymer, Optoelectronic devices, Spectroscopic techniques, Capacitance.

* Corresponding author: tharikaridmanji@gmail.com 


\section{INTRODUCTION}

In the emerging fields of nanotechnology, researchers have been more focused to innovate low-cost and eco-friendly materials in the modern world. Recent research on nano- composites composed of polymeric matrixes and nano-materials has been significantly increased due to the wide range of applications in optoelectronic devices with hybrid nanofilm electrodes. The attachment of metal or metal oxide nanoparticles with a polymeric matrix is useful for the development of thin films of novel properties. Some researchers have developed this polymer matrix of nano-composites using polypeptide structures of proteins ${ }^{[1]}$. Casein is the predominant protein in cow's milk which is about $80 \%$ of the total proteins present. It is a family of related phosphoproteins, $\alpha \mathrm{S} 1-, \alpha \mathrm{S} 2-, \beta$-, and $\kappa$ - casein, which forms micelles ${ }^{[2]}$. Casein has strongly acidic peptides of forty amino acids that seven contains eight phosphate groups and twelve carboxyl groups. The highly charged $\mathrm{N}$-terminal region of $\beta$-casein contains four of the five phosphates of the molecule and seven carboxyl groups ${ }^{[3]}$. The current study was to develop thin films using casein, which was extracted from cow's milk. In this work, we have also characterized some of the physical properties of casein thin films for applications in different optoelectronic devices.

\section{METHODOLOGY}

\subsection{Preparation of casein}

$300 \mathrm{ml}$ of cow's milk was added to a $500 \mathrm{ml}$ beaker and heated at $50{ }^{\circ} \mathrm{C}$, by measuring the temperature with a digital thermometer. $\mathrm{pH}$ of the milk suspension was measured by using EOTECH PC $2700 \mathrm{pH}$ meter which was found to be around 6.08. After heating, the cream floating on the milk suspension was removed by filtration. While stirring the milk suspension, acetic acid (99.7\%) was added drop-wise until casein was precipitated when the $\mathrm{pH}$ of the solution reached 4.5. Also different other organic acids such as lactic, formic and ascorbic and inorganic acids $\mathrm{H}_{3} \mathrm{PO}_{4}, \mathrm{H}_{2} \mathrm{SO}_{4}$ and $\mathrm{HNO}_{3}$ were used following the same procedure to precipitate casein from milk. The precipitate was collected by suction filtration and it was added to a mixture each of $50 \mathrm{ml}$ of diethyl ether and ethanol to remove the extra fat with vigorous stirring. Then again casein was filtered out by suction filtration, washed thoroughly with distilled water and allowed to dry in a desiccator after removal of water. The weight of the dried casein was measured by an electronic balance. Fine casein slurry was prepared by adding $1 \mathrm{~g}$ of dried casein to $2 \mathrm{ml}$ of distilled water and grinding at $400 \mathrm{rpm}$ in a ball mill for an hour.

\subsection{Preparation of casein thin films}

Fluorine doped tin oxide (FTO) coated glass plates were cleaned before coating the casein 
films. Cleaning process followed by washing the FTO glass $\left(1 \times 2 \mathrm{~cm}^{2}\right)$ consecutively with diluted nitric acid, tap water and distilled water in an ultrasonic bath and boiling in acetone at $60{ }^{\circ} \mathrm{C}$. After that the casein thick paste was spread out on the conducting side of the FTO plates using the doctor blade method and the film was dried in a hot stream of air. The electrodes of casein films of $1.0 \mathrm{~cm}^{2}$ size were made by removing the extra paste of the dried films on the glass plates.

\subsection{Characterization of casein}

The films of casein were characterized by using electrochemical and optical characterization techniques. The films were electrochemically characterized with the Mott-Schottky measurements and impedance spectroscopy using a computer coupled with Metrohm Autolab PGSTAT204 to find the flat band potential and impedance of the films respectively. The caseincoated glass plates served as the working electrodes while a platinum wire and a saturated $\mathrm{Ag} / \mathrm{AgCl}$ electrode served as counter and reference electrodes. The film of casein was optically characterized with UV-Visible spectroscopy by using UV-Visible spectrophotometer (Genesys 10s UV-Vis) and Fourier transform infrared spectra of casein samples were recorded using a WQF-510 FTIR spectrometer.

\section{RESULTS AND DISCUSSION}

The casein films deposited on conducting tin oxide glass plates were physically characterized by electrochemical and optical techniques. The impedance of the casein films were measured by drawing nyquist plots. Mott-Schotky plots were drawn to determine the flatband potential and donor density. UV visible and FTIR spectra were used to analyze the films optically

\subsection{Electrochemical characterization}

\subsubsection{Impedance spectroscopy}

The films of casein from organic and inorganic acids were characterized by electrochemical impedance spectroscopy (EIS). The impedance of the casein films was measured by the threeelectrode method using $0.01 \mathrm{~mol} \mathrm{dm}^{-3}$ sodium sulphate as the electrolyte at $\mathrm{pH} 10.7$ with standard $\mathrm{Ag} / \mathrm{AgCl}$ electrode and $\mathrm{Pt}$ wire as the counter electrode for different acids. In the impedance analysis, impedance was measured by varying the applied perturbation voltage in the frequency range from 0.1 to $10^{6} \mathrm{~Hz}$. The impedance of the films of casein from organic and inorganic acids are shown in figure 1 (a) and (b) respectively. Different plots shown in figures characterize by the presence of two arcs are almost equal in the electrochemical impedance spectra of casein prepared using different organic and inorganic acids. The two semicircles at high and low frequency regions in the Nyquist plots represent charge transport resistance in the counter electrode and the casein film respectively. 

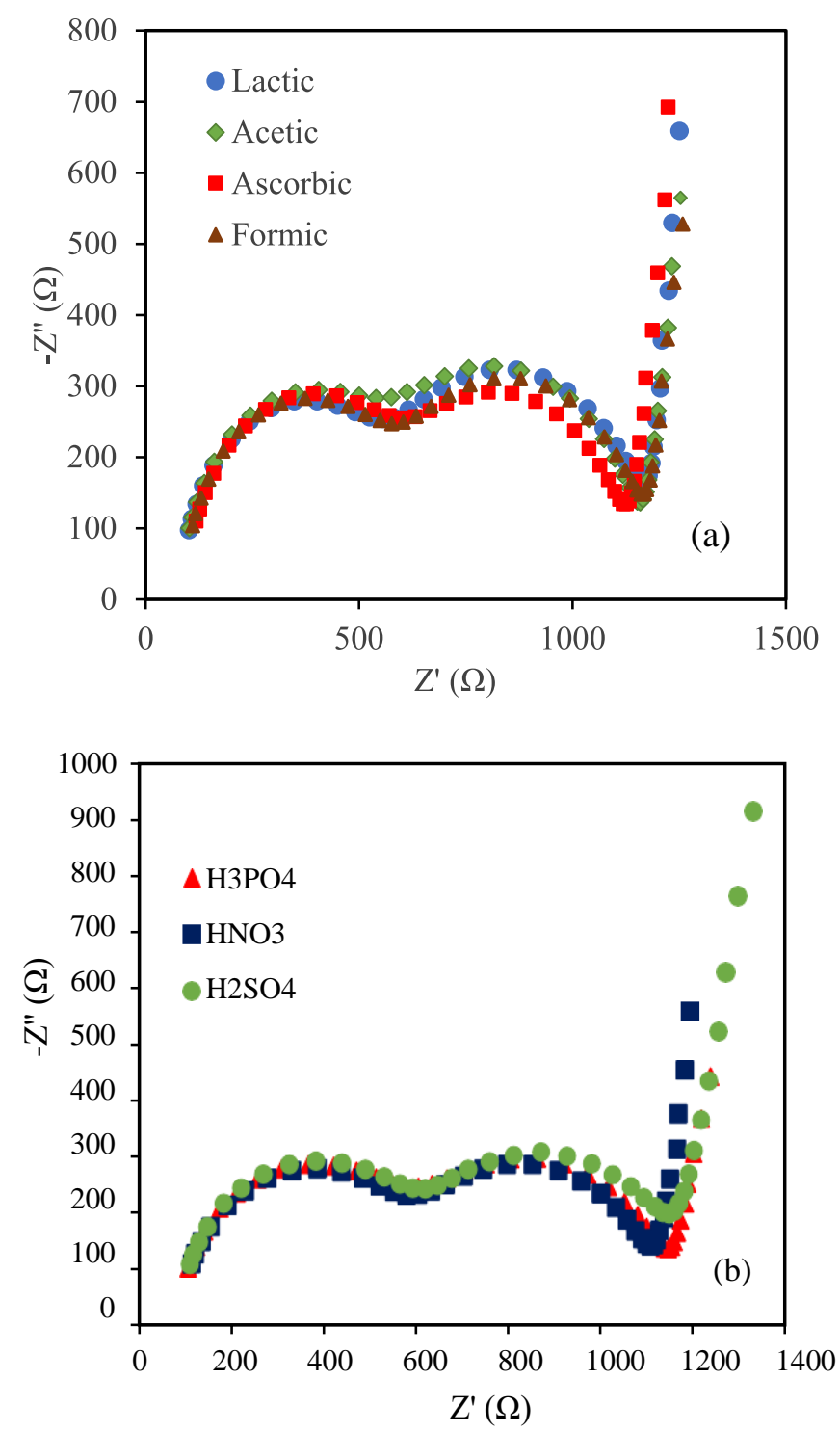

Figure 1: Nyquist plot of casein films made using (a) organic acids and (b) inorganic acids

\subsubsection{Mott-Schottky measurements}

Mott-Schottky (MS) analysis is a well-known and powerful tool to determine the flat band potential (or the electrode work function) and the donor concentration (intrinsic carrier concentration) of semiconductor materials. Although MS theory is based on the properties of an abrupt semiconductor junction, it has already been applied in organic materials. The MottSchottky plot of casein-coated FTO films was measured in the three-electrode system using $0.01 \mathrm{~mol} \mathrm{dm}^{-3}$ sodium sulphate as the electrolyte at $\mathrm{pH} 10.7$ with standard $\mathrm{Ag} / \mathrm{AgCl}$ electrode and Pt wire as the counter electrode. Mott-Schottky analysis was done for all casein samples prepared using different acids. The Mott-Schottky measurements of thin films of casein from organic and inorganic acids are shown in Figures 2 (a) and (b). The positive slopes in the MS plots of all the samples is evident for casein to be n-type material. The flat band potential of casein films of different organic and inorganic acids was found as $-0.61 \mathrm{~V}$ by analyzing the 
Mott-Schottky plots.
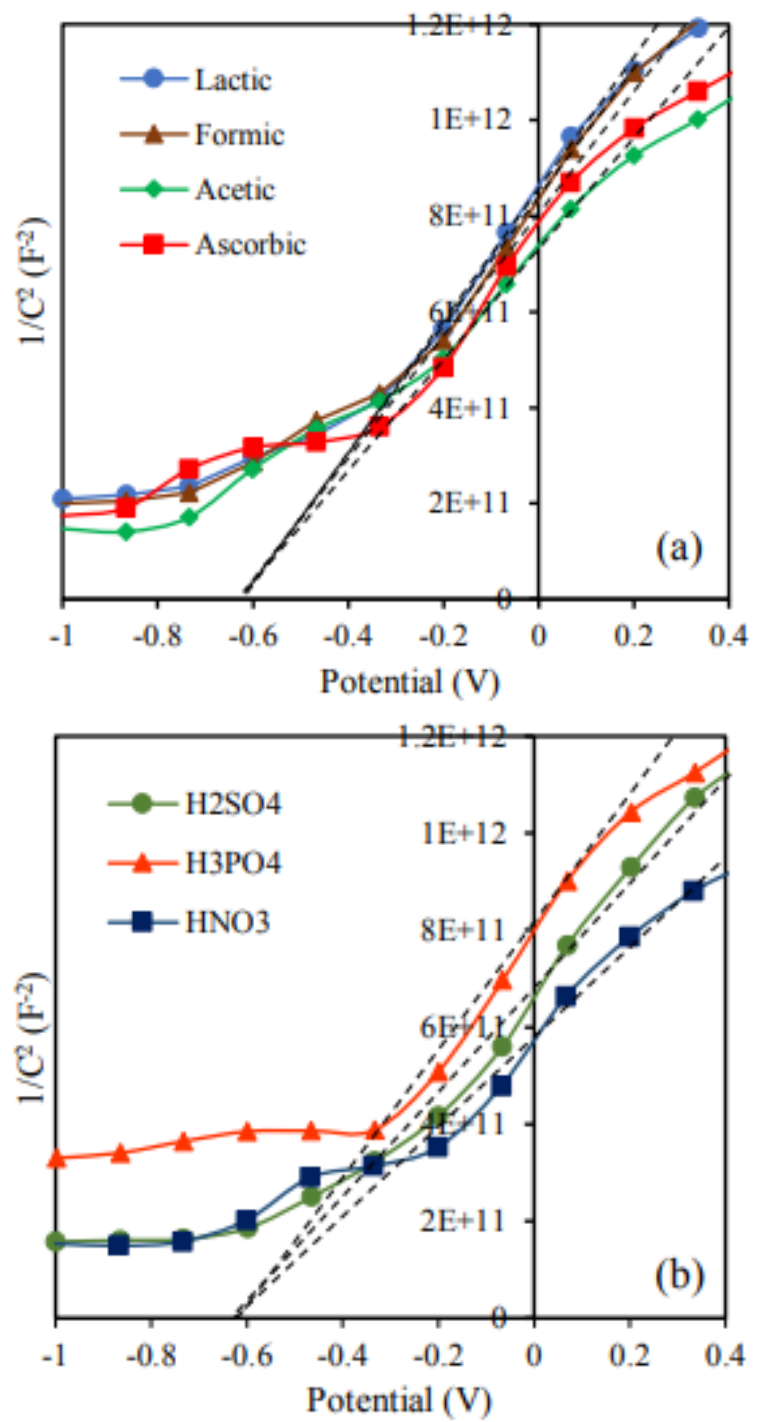

Figure 2: Mott-Schottky plots of casein film made using (a) organic and (b) inorganic acids.

Mott-Schottky relationship use to analyze flat band potential is described by equation $1^{[5]}$.

$$
\frac{1}{C^{2}}=\frac{2}{e \varepsilon \varepsilon_{0} N}\left(V-V_{f b}-\frac{k T}{e}\right)
$$

Where $C$ is the capacitance, $\varepsilon_{0}$ is the permittivity of free space, $e$ is the electronic charge, $N$ is the donor density, $V$ is the applied potential, $V_{F B}$ is the flat band potential, $k$ is the Boltzmann constant and $T$ is the absolute temperature. 
A thin film of casein prepared using acetic acid was characterized by the Mott-Schottky measurements to find the donor density. The donor concentration of the sample was determined from the slope of the Mott-Schottky plot and found to be $8.05 \times 10^{30} \mathrm{~cm}^{-3}$ for the films made precipitating casein with acetic acid. It can also be evident from figure 3 that the donor density slightly changes with the acid used to precipitate casein.

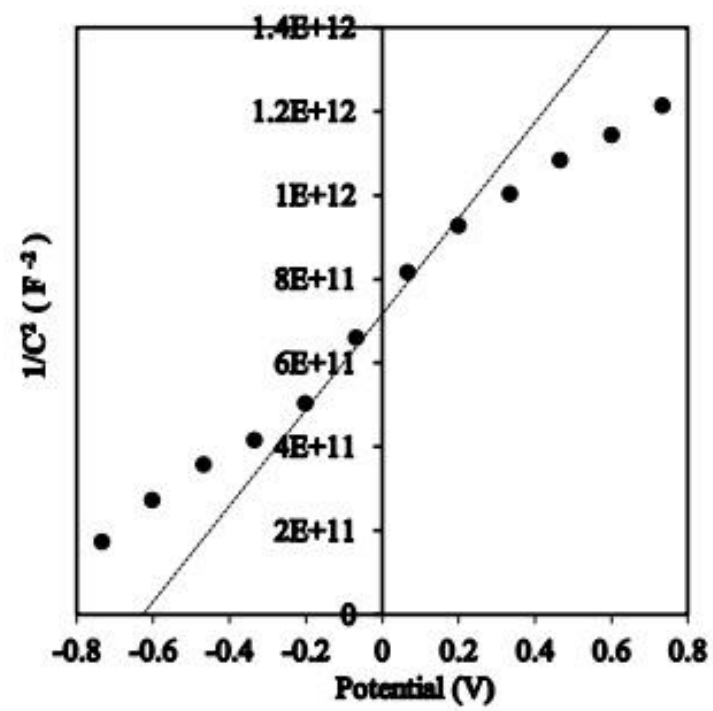

Figure 3: The Mott-Schottky plot of the thin film of casein by acetic acid

\subsubsection{Two-electrode Impedance measurements}

After analyzing Mott-Scotty results and electrochemical impedance measurements of different acids, progressive results and calculations of casein isolated using acetic acid were taken using two electrode method to analyze the conductivity of casein thin films.

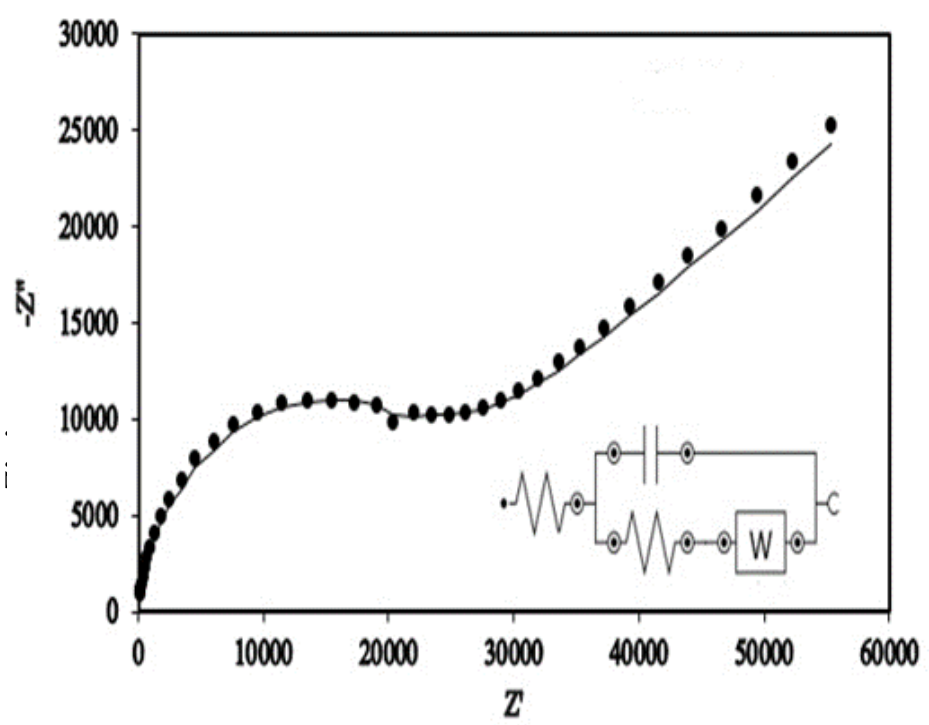

Figure 4: Nyquist plot of the thin film of casein measured using two electrodes that prepared using acetic acid and equivalent circuit of the thin film.

Figure 4 shows the impedance spectra and insert depicts the resulting equivalent circuit of thin film of casein prepared by using acetic acid. The X-axis is the real part of the impedance 
and the $\mathrm{Y}$-axis is the imaginary part of the impedance. The simulated results of the equivalent circuit of the film are given in table 1.

Table 1: Simulated results of the equivalent circuit for thin film of casein

\begin{tabular}{|l|c|c|c|}
\hline $\begin{array}{l}\text { Series resistance } \\
\mathrm{R}_{1}(\Omega)\end{array}$ & $\begin{array}{c}\text { Charge transfer } \\
\text { resistance } \mathrm{R}_{2}(\Omega)\end{array}$ & $\begin{array}{c}\text { The capacitance } \\
\text { of thin film } \mathrm{C} \\
(\mu \mathrm{F})\end{array}$ & $\begin{array}{c}\text { Warburg } \\
\text { impedance W } \\
\left(\mathrm{m} \Omega^{-1} \mathrm{~s}^{1 / 2}\right)\end{array}$ \\
\hline 216 & $26.6 \times 10^{3}$ & $194 \times 10^{-6}$ & $1.34 \times 10^{3}$ \\
\hline
\end{tabular}

The value of electrical conductivity $\sigma(\mathrm{S} / \mathrm{m})$ of the thin film of casein was calculated using the following equation.

$$
\sigma=\mathrm{L} / \mathrm{RA}
$$

Where $\mathrm{A}$ is the cross-section area of the measured surface $\left(\mathrm{m}^{2}\right), \mathrm{L}$ is the thickness of the sample (m) which was calculated gravimetrically. R is the resistance $(\Omega)$. The value of electrical conductivity of the thin film of casein was found to be $1.13 \times 10^{-2} \mathrm{mS} / \mathrm{m}$.

We have carried out the impedance spectroscopic measurements on casein films as a parallel plate capacitor which was used to calculate the dielectric constant $(K)$ of the casein

$$
K=\frac{C d}{\varepsilon_{0} A}
$$

where $\mathrm{C}$ is the capacitance, $d$ is the thickness of the film, $A$ is the area of the film and $\varepsilon_{o}$ is the permittivity of free space $\left(\varepsilon_{o}=8.85 \times 10^{-12} \mathrm{C}^{2} \mathrm{~N}^{-1} \mathrm{~m}^{-2}\right)$. The dielectric constant of the synthesis casein sample is found to be 6.6. It is matching with the standard value of the dielectric constant of casein which is in the range $6.1-6.8^{[4]}$.

\subsection{Optical characterization}

Casein was optically characterized with UV-Visible spectra by using UV-Visible spectrophotometer (Genesys 10s UV-Vis) and Fourier transform infrared spectra of casein samples were recorded using a WQF-510 FTIR spectrometer for further analysis. 


\subsubsection{UV-visible spectroscopic analysis}
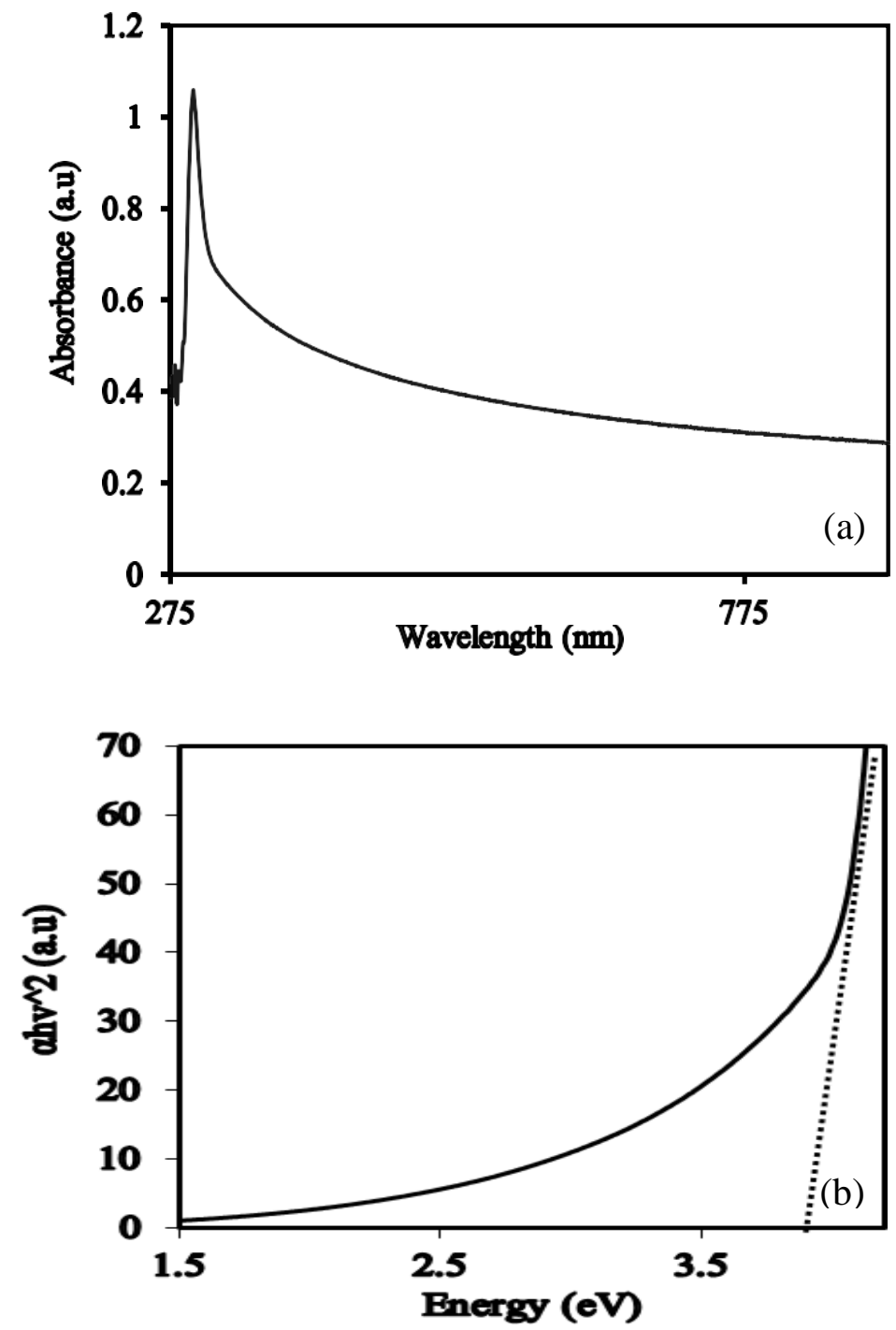

Figure 5: (a) UV-visible spectra of thin film of casein and (b) Tauc plot of casein derive from spectroscopic data.

The thin film of synthesized casein has a strong absorption at $296 \mathrm{~nm}$. The bandgap of synthesized casein was determined with the tauc plot that was drawn using the absorption data which was found as $3.9 \mathrm{eV}$. Figure 6 depicts the energy level positions of the conduction band and valence band of casein with respect to the normal hydrogen electrode determined from the above data. High bandgap of the casein confirms that it behaves as an insulator intrinsically. This insulating behavior of casein is helpful to make composites combining with some metal or metal oxide to develop thin film of electrodes for optoelectronic devices. 


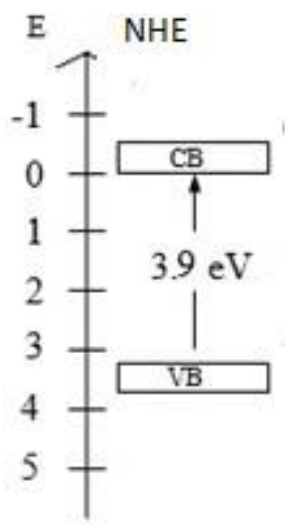

Figure 6: Energy band alignment of casein

\subsubsection{FTIR Analysis}

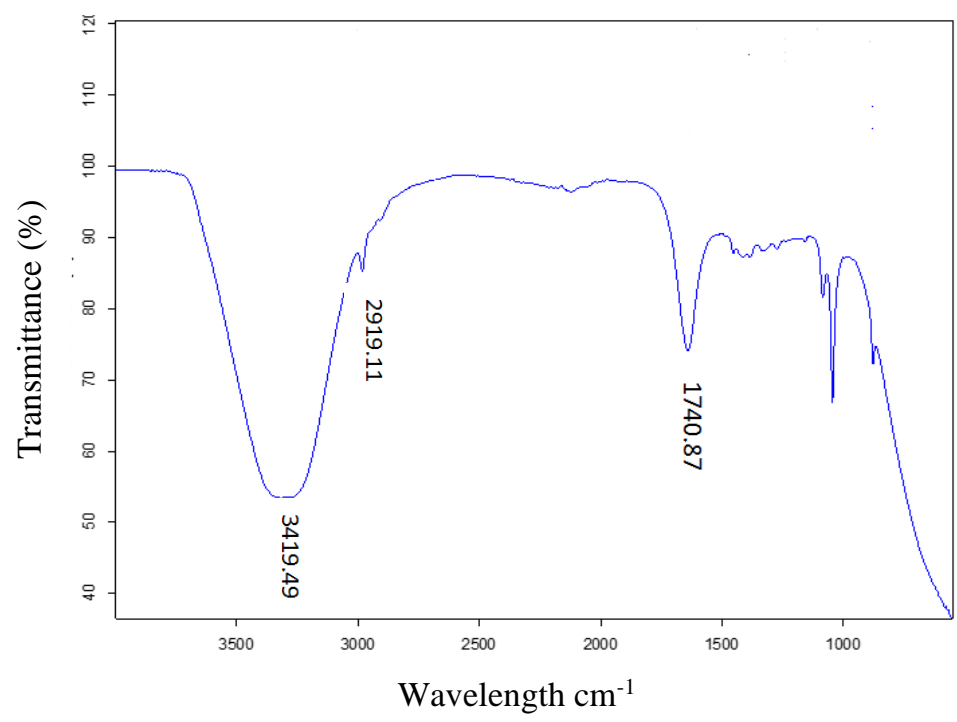

Figure 7: FTIR spectra of synthesis casein sample

Fourier transform infrared (FTIR) analysis was used to determine the specific vibrational groups in casein. The structure of the casein sample when observed by Fourier transform infrared spectroscopy, vibrational bands of carboxyl $(\mathrm{COOH})$ groups at $3419.49 \mathrm{~cm}^{-1}$ was evident. Bands at 2919 and $2852 \mathrm{~cm}^{-1}$ are for symmetric and asymmetric stretching bonds of $\mathrm{CH}_{2}$ groups. Those vibrations indicate the presence of amino acids with a higher concentration of $\mathrm{CH}_{2}$ groups, such as lysine, which contains six carbon atoms in the side chains as well as arginine that contains three $\mathrm{CH}_{2}$ groups in line. Strong vibrational bands at $1740.87 \mathrm{~cm}^{-1}$ indicate the presence of carbonyl groups $(\mathrm{C}=\mathrm{O})$. Usually, bands of the carbonyl groups occur in the range of $1725-1750 \mathrm{~cm}^{-1}$ in the presence of strong hydrogen bonding. Furthermore, vibration peaks of carbonyl groups can be seen in the interval between 1500 and $1000 \mathrm{~cm}^{-1}$ [6]. 
Table 2: Summary of functional groups in the Casein sample from FTIR spectra

\begin{tabular}{|c|c|}
\hline Functional group & Wavenumber $\left(\mathrm{cm}^{-1}\right)$ \\
\hline$-\mathrm{COOH}$ & 3419.49 \\
\hline $\mathrm{CH}_{2}-$ & $2919.11-2852.05$ \\
\hline $\mathrm{C}=\mathrm{O}$ & 1740.87 \\
\hline $\mathrm{NH}-\mathrm{C}=\mathrm{O}$ & 1639.52 \\
\hline
\end{tabular}

\section{CONCLUSION}

The current study was aimed to prepare casein thin films from cow's milk on glass substrates and physically characterize them using electrochemical and spectroscopic analysis. The calculated electrical conductivity of the casein from cow's milk was $1.13 \times 10^{-2} \mathrm{mS} / \mathrm{m}$ and the dielectric constant was 6.6. The Mott-Schottky plot provided that the casein has an n- type conductivity. The value of the flat band potential of the casein sample was $-0.61 \mathrm{~V}$. In the optical characterizations, the value of the maximum absorption peak of the UV-visible spectra was at $296 \mathrm{~nm}$. The bandgap of casein calculated from tauc plot was $3.9 \mathrm{eV}$ which was an evidence that it is more or less an insulating material. It was also observed no significant difference in the above measurements depending on the acid used to prepare casein.

\section{REFERENCES}

1. Vilela, C.,Pinto, R.J.B., Pinto, S., Marques, P., Silvestre, A., Barros, C.S.D.R.F., Polysaccharide Based Hybrid Materials, Springer Cham, Springer Nature Switzerland AG 2018.

2. Yao, Y., Wang, H., Wang, R.,Chai, Y., Preparation and characterization of homogeneous and enhanced casein protein-based composite films via incorporating cellulose microgel, Sci. Rep. 91 (2019) 1221. DOI: https://doi.org/10.1038/s41598-018-37848-1)

3. Singh, A., Bajpai, J.,Tiwari, A., Bajpai, A.K., Designing casein-coated iron oxide nanostructures (CCIONPs) as superparamagnetic core-shell carriers for magnetic drug targeting, Prog Biomater,4,(2015) 39-53. DOI: https://doi.org/10.1007/s40204-0140035-6

5. https://www.clippercontrols.com/pages/Dielectric-Constant-Values.html

6. Ajward, N. F., Wickramasinghe, G. C., Rajendra, J. C. N., Perera, V. P. S., Enhancement of performance of Dye Sensitized Solar Cells by dip coating silica on Nano structured $\mathrm{TiO}_{2}$ films, Solar Asia International Conference. (2018) 90-97

7. Sirocic, A.P, Krehula, L.J.K, Katancic, Z., Hrnjak-Murgic, Z., Characterization of Casein Fractions - Comparison of Commercial Casein and Casein Extracted from Cow's Milk, Chem.Biochem.Eng.Q.30(2016)501-509.

DOI: https://doi.org/10.15255/CABEQ.2015.2311 